\title{
Sıçan uterin horn modelinde enoksaparin ve rapamisinin adezyon oluşumuna etkilerinin karşılaştırılması
}

\section{Comparison of effects of enoxaparin and rapamycin on adhesion formation in a rat uterine horn model}

\author{
Ahter Tanay Tayyar*, Tuncay Özgün, Hülya Akgün \\ Kadın Hastalıkları ve Doğum Anabilim Dalı (Dr. A. T. Tayyar, Doç. Dr. T. Özgün), Patoloji \\ Anabilim Dalı (Doç. Dr. Hülya Akgün), Erciyes Üniversitesi Tıp Fakültesi TR 38030 Kayseri.
}

\begin{abstract}
Özet
Amaç. Birçok çalışmada düşük molekül ağırlıklı heparinlerin (DMAH) postoperatif adezyon gelişimini önlemede etkili olduğu, bazı çalışmalarda da rapamisinin immünosüpresif bir ajan olarak postoperatif adezyon gelişimini azaltabileceği saptanmıştır. Bu deneysel çalışmada bir DMAH olan enoksaparin ile rapamisinin tek tek veya birlikte adezyon oluşumu üzerine etkileri sıçan uterin horn modelinde incelendi. Yöntem. Çalışmada ağırlıkları 200-250 gr arasında olan 40 adet Wistar-Albino dişi sıçan kullanıldı. Sıçanların karın duvarına anestezi altında steril koşullarda $3 \mathrm{~cm}$ 'lik orta hat kesisi yapıld. Her iki uterin hornda antimezenterik yüzeye 8-10 adet unipolar koterizasyon uygulandı ve antimezenterik yüzeyler $4 / 0$ polidioksanon ile karın ön duvar peritonuna dikildi. Siçanlar kontrol, enoksaparin, rapamisin ve enoksaparin ve rapamisin gruplarına $(\mathrm{n}=10)$ ayrıldı. Kontrol grubunda adezyon önleyici tedavi uygulanmadan karın katları usulüne uygun olarak kapatıldı. Enoksaparin grubunda 14 gün süreyle enoksaparin $50 \mathrm{U} / \mathrm{kg}$ intraperitoneal olarak uyguland. Rapamisin grubunda 14 gün süreyle $0,8 \mathrm{mg} / \mathrm{kg}$ oral yoldan gavaj tüpüyle rapamisin uygulandı. Enoksaparin ve rapamisin grubunda 14 gün süreyle enoksaparin 50 $\mathrm{U} / \mathrm{kg}$ intraperitoneal olarak verildi, ayrıca aynı süreyle $0,8 \mathrm{mg} / \mathrm{kg}$ oral yoldan gavaj tüpüyle rapamisin ilave olarak uygulandı. Siçanların tümü 14 gün sonra letal doz pentobarbital ile öldürülerek orta hat kesisi ile laparotomi yapılarak adezyon gelişimi gözle ve histopatolojik olarak değerlendirildi. Bulgular. Makroskopik ve mikroskopik olarak incelendiğinde çalışma gruplarının adezyon şiddetleri benzer bulundu ( $>0,05)$. İlaç uygulanan grupların adezyon yaygınlı̆̆ 1 ve total adezyon skorları kontrol grubununkine göre daha düşük bulundu $(p<0,05)$. İlaç uygulanan grupların adezyon yaygınlığı ve total adezyon skorları arasında anlamlı fark bulunmadı $(\mathrm{p}>0,05)$. Sonuç. Enoksaparin ve rapamisin benzer düzeylerde total adezyonu önlemekte, bunu yaparken adezyon şiddetinden daha çok adezyon yaygınlığını azaltarak etkili olmaktadır. Birlikte kullanımlarında ise adezyon oluşumu üzerine etkileri sinerjistik değildir.
\end{abstract}

Anahtar sözcükler: Düşük molekül ağırlıklı heparin, enoksaparin, rapamisin, peritoneal adezyon

\begin{abstract}
Aim. Several studies have demonstrated that low molecular weight heparins (LMWHs) decreased postoperative adhesion formation. Also, a few studies have noted that immunosuppressive agent rapamycin decreased postoperative adhesion formation. In this experimental study, we aimed to investigate the effect of enoxaparin and rapamycin alone and in combination on the adhesion formation in a rat uterine horn model. Methods. Our study included 40 Wistar-Albino rats weighing between 200-250 g. Control and three study groups were formed including 10 rats. In sterile condition, we performed $3-\mathrm{cm}$ midline incision of abdominal wall under general anesthesia. On the antimesenteric surface of both uterine horns, 8-10 unipolar electrocauterization were applied. Later these antimesenteric surfaces were sutured to abdominal sidewalls with 4.0 polydioxanone. In the control group, no therapy was applied after surgery and incision was closed according to general surgical rules. In the enoxaparin group, enoxaparin $50 \mathrm{U} / \mathrm{kg}$ was applied intraperitoneally for 14 days. In the rapamycin group, rapamycin $0.8 \mathrm{mg} / \mathrm{kg}$ was applied orally with feeding tube for 14 days. In the enoxaparin plus rapamycin group, enoxaparin $50 \mathrm{U} / \mathrm{kg}$ was applied intraperitoneally and rapamycin $0.8 \mathrm{mg} / \mathrm{kg}$ orally with the feeding tube for 14 days. The animals were sacrificed by lethal dose pentobarbital 14 days after surgery and a midline
\end{abstract}


laparatomy was carried out and abdominal cavity was inspected for the presence of adhesion and adhesion samples were obtained for histopathological examination. Results. According to the findings of macroscopic and microscopic evaluation, the scores of adhesion severity were found comparable among the enoxaparin, rapamycin and enoxaparin plus rapamycin groups ( $\mathrm{p}>0.05)$; however, the scores of adhesion extent and total adhesion scores were significantly lower in the drug groups compared to the control group $(\mathrm{p}<0.05)$. There was no significant difference among the three drug groups with regard to all the adhesion scores $(p>0.05)$. Conclusion. Enoxaparine and rapamycin prevent total adhesion similarly, however, this effect is considerable on the extent of adhesion rather than the severity of adhesion. Combination of enoxaparin and rapamycin did not show synergistic effect on adhesion formation.

Keywords: Low molecular weight heparin, enoxaparin, rapamycin, peritoneal adhesion

Geliş tarihi/Received: 16 Ocak 2013; Kabul tarihi/Accepted: 05 Ağustos 2013

\section{* İletişim adresi:}

Dr. Ahter Tanay Tayyar, Kadın Hastalıkları ve Doğum Anabilim Dalı, Erciyes Üniversitesi Tıp Fakültesi, TR-38039 Kayseri. E-posta: drahtertayyar@yahoo.com

\section{Giriş}

Pelvik intraperitonel adezyon oluşumunun engellenmesi üreme cerrahisinde hala önemli yer tutmaktadır. Adezyon formasyonu ile infertilite, ektopik gebelik, kronik pelvik ağrı ve intestinal obstrüksiyon ortaya çıkabilmektedir. Ayrıca reoperasyonlarda ameliyat süresi uzamakta, komşu organlara travma olasılığı ve kanama riski artmaktadır. Yaşanan sorunların giderilmesi için yapılan araştırma ve tedavi giderleri önemli ekonomik yüke neden olmaktadir [1-3].

Adezyon oluşumunu önlemek amacıyla günümüze kadar birçok adjuvanlar hayvan ve insan modellerinde denenmiştir. Ancak herkes tarafından etkinliği kabul edilmiş bir adjuvanın olmayışı hayal kırıcıdır. Bu sebeple üreme cerrahisinde adezyon oluşumunu önlemeye yönelik çalışmalar yoğun olarak devam etmektedir [4, 5].

Uygun cerrahi tekniğin yanında adezyonları önlemek amacıyla fibrinolitik ve antiinflamatuar ajanlar, mekanik ayırım yapan solüsyon ve bariyer materyalleri, antibiyotikler ve antikoagülanlar kullanılmıştır $[5,6]$.

Düşük molekül ağırlıklı heparinlerin (DMAH) birçok çalışmada adezyonu önlemede kullanabileceği gösterilmiştir. Ancak bu etkinin yeterli olmaması nedeniyle başka ajanlar da araştırılmıştır [5].

Bu çalışmada birçok araştırmada adezyon önleyici etkisi gösterilmiş olan DMAH'lerden biri olan enoksaparin ile mezotelyal hücre ve makrofajların proliferasyonunu inhibe eden $\mathrm{T}$ lenfositlerin proliferasyon ve diferansiyasyonunu duraklatan ve adezyon oluşumunda rol alan transforming büyüme faktörü (TGF)- $\beta$ sentezini azaltan immünosüpresif bir ajan olan rapamisinin [7,8] tek başlarına veya birlikte kullanımlarında adezyon oluşumu üzerine olan etkileri sıçan uterin horn modelinde incelendi.

\section{Gereç ve yöntem}

Deneysel çalışmamız Erciyes Üniversitesi Tıp Fakültesi Hakan Çetinsaya Deneysel ve Klinik Araştırma Merkezinde yapıldı. Deneysel çalışmamızda aynı merkezden alınan ve ağırlıkları 200-250g olan Wistar-Albino tipi dişi sıçanlar kullanıldı. Siçanlar randomize edilerek onarlık 4 çalışma gruba ayrıldı: kontrol, enoksaparin, rapamisin ve enoksaparin ve rapamisin gruplar. Hayvanlar çalışma sürecinde ayrı kafeslerde tutuldu ve standart diyet ile beslendiler.

Hayvanlar operasyondan 12 saat önce aç bırakıldılar. Tüm işlemler intraperitoneal ketamin hidroklorid $(10 \mathrm{mg} / \mathrm{kg})$ uygulaması altında gerçekleştirildi. Anestezi sonrası 
insizyon yapılacak alan traş edildi ve povidon iyodin solüsyonu ile boyandı. Hayvanlara $3 \mathrm{~cm}$ 'lik orta hat abdominal insizyon ile laparotomi yapıldı. Uterin hornların antimezenterik yüzeylerine noktasal tarzda 8-10 kez koterizasyon uygulandı. Sonrasında peritoneal yüzeyde, bisturi ile noktasal hemoraji meydana gelene kadar peritoneal hasar oluşturuldu. Daha sonra hornlar 4/0 açık polidioksanon sütür kullanılarak karın ön duvar peritonuna asıldı. Bu işlemi takiben fasya ve periton birlikte $4 / 0$ polidioksanon sütür ve cilt 3/0 ipek kullanılarak kapatıld1.

Adezyon oluşturucu cerrahi işlem sonrası çalışma gruplarına aşağıdaki işlemler uyguland1:

- Kontrol grubunda herhangi bir ilaç tedavisi verilmedi.

- Enoksaparin grubunda enoksaparin $50 \mathrm{U} / \mathrm{kg}$ intraperitoneal olarak 14 gün süre ile verildi.

- Rapamisin grubunda rapamisin $0,8 \mathrm{mg} / \mathrm{kg}$ oral yoldan gavaj tüpüyle 14 gün süre ile uygulandi.

- Enoksaparin ve rapamisin grubuna enoksaparin $50 \mathrm{U} / \mathrm{kg}$ intraperitoneal olarak ve rapamisin $0,8 \mathrm{mg} / \mathrm{kg}$ oral yoldan gavaj tüpüyle 14 gün süre ile uyguland.

- Çalışmada kullanılan enoksaparin (Clexane flakon) Aventis Pharma Sanayi ve Ticaret AŞ'den rapamisin (Rapamune tablet) ise Wyetth İlaç Sanayi ve Ticaret AŞ'den sağland1.

- Postopreatif 2. günde karın duvarı yara yeri açılmasına bağlı olarak kombine gruptan bir adet sıçan öldü. Çalışmaya 39 sıçan ile devam edildi.

- On dördüncü gün letal dozda pentobarbital verilerek hayvanlar öldürüldü ve sol paramedian insizyonla ikinci bakış laparotomi yapılıp adezyon gelişimi incelendi. Adezyon skorlamaları çalışma grupları bilinmeden yapıldı. Adezyon skorlaması yapılırken adezyon şiddeti Knightly sınıflamasına (Tablo 1) ve adezyon yaygınlığı ise Linsky sinıflamasına (Tablo 2) uygun olarak yapıldı [9]. Adezyon şiddet ve yaygınlık skorları toplanarak toplam adezyon skoru hesapland1.

Tablo 1. Adezyon şiddet skorlaması (Knightly sınıflaması).

\begin{tabular}{ll}
\hline Evre & Tanımlama \\
\hline 0 & Adezyon yok \\
1 & İnce film şeklinde adezyonlar; dokulardan kolaylıkla ayrılabilen ince adezyon \\
2 & Diseksiyon sırasında doku hasarı oluşturmayan gergin adezyon \\
3 & Diseksiyon sırasında serozal doku hasarı oluşturan gergin adezyon \\
4 & Diseksiyon sırasında tam kat doku hasarına yol açan sert adezyon \\
\hline
\end{tabular}

Tablo 2. Adezyon yaygınlık skorlaması (Linsky sınıflaması).

\begin{tabular}{ll}
\hline Evre & Tanımlama \\
\hline $\mathbf{0}$ & Adezyon yok \\
$\mathbf{1}$ & Travmatize alanın \%1-25'inde adezyon mevcut \\
$\mathbf{2}$ & Travmatize alanın \%26-50'sinde adezyon mevcut \\
$\mathbf{3}$ & Travmatize alanın \%51-75'inde adezyon mevcut \\
$\mathbf{4}$ & Travmatize alanın \%76-100'ünde adezyon mevcut \\
\hline
\end{tabular}

Makroskopik skorlamadan sonra mikroskopik skorlama amaciyla histopatolojik inceleme için her uterin horn karın ön duvar peritonuyla beraber eksize edildi. Bu materyaller \%10'luk tamponlanmış formol içinde fikse edildi. Elde edilen piyeslerden parafin bloklara gömülerek $5 \mu \mathrm{m}$ kalınlıkta kesitler oluşturuldu. Bunlar hematoksilen-eozin ile boyanarak 1 ş1k mikroskopuyla incelendi. Histopatolojik adezyon değerlendirmesi Zühlke'nin mikroskopik adezyon sınıflamasına [10] uygun olarak yapıldı (Tablo 3). 
Tablo 3. Mikroskopik adezyon evrelemesi (Zühlke sınıflaması).

Evre 1 Zayıf konnektif doku, zengin hücre, eski ve yeni fibrin, ince retikülin fibriller

Evre 2 Hücreler ve kapiller damarların olduğu konnektif doku, nadir kollajen lifleri

Evre 3 Daha kalın konnektif doku, nadir hücreler, daha fazla damarlar, nadir elastik

Evre 3 ve düz kas lifleri

Evre 4 Eski kalın granülasyon dokusu, hücreden fakir, serozal tabakaların zor ayrılması

\section{Ístatistiksel analiz}

Veriler ortalama \pm standart sapma (SD) ve ortanca (en küçük-en büyük) olarak gösterildi. Makroskopik ve histopatolojik olarak elde edilen adezyon skorlarının karşılaştırılmasında Kruskal-Wallis testi uygulandı ve anlamlı fark bulunduğunda gruplar arası farklılığı tespit etmek için Bonferroni (Dunn) testi kullanıldı. $\mathrm{P}<0,05$ ise istatistiksel olarak anlamlı kabul edildi.

\section{Bulgular}

\section{Makroskopik değerlendirme}

Adezyon yaygınlık ve şiddet skorları her sıçanda mevcut olan iki uterin horn için ayrı ayrı değerlendirildi (toplam 78 uterin horn). Çalışma gruplarının adezyon şiddet skorları Tablo 4'de sunuldu. Çalışma gruplarının adezyon şiddet skorları arasında istatistiksel olarak anlamlı bir fark bulunmadı $(\mathrm{p}=0,083)$.

Tablo 4. Adezyon şiddet skoru.

\begin{tabular}{lll}
\hline & Ortalama \pm SD & Ortanca (en küçük-en büyük) \\
\hline Kontrol & $2,15 \pm 0,58$ & $2(1-3)$ \\
Enoksaparin & $1,95 \pm 0,94$ & $2(1-4)$ \\
Rapamisin & $1,6 \pm 0,59$ & $2(1-3)$ \\
Enoksaparin ve rapamisin & $1,83 \pm 0,98$ & $2(1-4)$ \\
\hline \multicolumn{2}{l}{ Ortalamalar arasında anlamlı fark bulunmadı (Kruskal-Wallis test; $\mathrm{p}=0,083)}$.
\end{tabular}

Çalışma gruplarının adezyon yaygınlık skorları Tablo 5'te sunuldu. Adezyon yaygınlık skorları karşılaştırıldığında kontrol grubununkine göre ilaç gruplarının adezyon yaygınlık skorları anlamlı olarak düşük bulundu $(\mathrm{p}=0,01)$. İlaç gruplarının adezyon yaygınlık skorları arasında istatistiksel olarak anlamlı bir fark izlenmedi $(\mathrm{p}>0,05)$.

Tablo 5. Adezyon yaygınlık skoru.

\begin{tabular}{lll}
\hline & Ortalama \pm SD & Ortanca (en küçük-en büyük) \\
\hline Kontrol & $2,0 \pm 2,72^{\mathrm{a}}$ & $2(1-4)$ \\
Enoksaparin & $1,55 \pm 0,75$ & $1(1-3)$ \\
Rapamisin & $1,25 \pm 0,44$ & $1(1-2)$ \\
Enoksaparin ve rapamisin & $1,33 \pm 0,84$ & $1(1-4)$ \\
\hline \multicolumn{2}{l}{$\mathrm{P}=0,001$ ilaç gruplarına göre (Kruskal-Wallis test). } \\
\hline
\end{tabular}

Çalışma gruplarının total adezyon skorları Tablo 6'da sunuldu. Total adezyon skorları karşılaştırıldığında kontrol grubununkine göre ilaç gruplarının adezyon yaygınlık skorları anlamlı olarak düşük bulundu $(\mathrm{p}=0,002)$. İlaç gruplarının total adezyon skorları arasında istatistiksel olarak anlamlı bir fark izlenmedi $(\mathrm{p}>0,05)$.

Tablo 6. Total adezyon skoru.

\begin{tabular}{|c|c|c|}
\hline & Ortalama \pm SD & Ortanca (en küçük-en büyük) \\
\hline Kontrol & $4,15 \pm 1,08^{\mathrm{a}}$ & $4(2-7)$ \\
\hline Enoksaparin & $3,50 \pm 1,63$ & $3(2-7)$ \\
\hline Rapamisin & $2,85 \pm 0,87$ & $3(2-4)$ \\
\hline Enoksaparin ve rapamisin & $3,16 \pm 1,68$ & $3(2-8)$ \\
\hline
\end{tabular}




\section{Histopatolojik değerlendirme}

Çalışma gruplarının mikroskopik adezyon skorları Tablo 7'de sunuldu. Çalışma gruplarının mikroskopik adezyon skorları benzer bulundu $(\mathrm{p}=0,369)$.

Tablo 7. Mikroskopik adezyon skoru.

\begin{tabular}{lll}
\hline & Ortalama \pm SD & $\begin{array}{l}\text { Ortanca } \\
\text { (en küçük-en büyük) }\end{array}$ \\
\hline Kontrol & $2,7 \pm 0,73$ & $3(2-4)$ \\
Enoksaparin & $2,5 \pm 0,6$ & $2(2-4)$ \\
Rapamisin & $2,35 \pm 0,48$ & $2(2-3)$ \\
Enoksaparin ve rapamisin & $2,38 \pm 0,6$ & $2(2-4)$ \\
\hline \multicolumn{2}{l}{ Ortalamalar arasında anlamlı fark bulunmadı (Kruskal-Wallis test; $\mathrm{p}=0,369)}$. \\
\hline
\end{tabular}

\section{Tartıșma}

Pelvik cerrahi yüksek oranda adezyon formasyonuna neden olmakta ve infertilite hastalarında pelvik adezyonlar halen önemli bir klinik problem olmaya devam etmektedir. Ayrıca adezyonlara bağlı olarak kronik pelvik ağrı, barsak tıkanması gibi sorunlar da ortaya çıkabilmektedir $[1,2]$.

Postoperatif adezyon gelişimini önlemek için birçok yöntem araştırılmıştır. Bunların birçoğu hayvanlar üzerinde deneysel olarak yapılmıştır. Çalışmamızda kullandığımız deneysel adezyon oluşturma modeli birçok araştırmacı tarafından kullanılmış güvenilir bir yöntemdir. Adezyon skorlamaları içinde geniş kabul gören Linsky ve Knightly sınıflamaları kullanılmıştır [9].

Enoksaparin grubunda adezyon şiddeti kontrol grubu dahil diğer gruplardan istatistiksel olarak farkl1l1k göstermezken adezyon yaygınlık ve total adezyon skorları kontrol grubuna göre istatistiksel olarak anlamlı derecede düşük bulunmuştur. Ancak enoksaparin grubunda saptanan adezyon yayginlık ve total adezyon skorları rapamisin ve kombine grupların adezyon skorları ile benzerlik göstermiştir. Ayrıca enoksaparin grubunun mikroskopik adezyon skoru diğer gruplarla gere farkl1l1k arz etmemiştir.

Deneysel çalışmamızda kullandığımız enoksaparin 4500 dalton ağırlığındadır. Anfraksiyone heparine göre tüm faktörleri etkilemediğinden kanama yapma potansiyeli düşüktür. Plazma proteinlerine de az bağlandığından etkinliği düşük dozlarda olabilmektedir. Heparin in vivo olarak antitrombin III ile kompleks oluşturur ve trombin parçalanmasını artırır. Bu kompleks özellikle faktör Xa olmak üzere trombin dışındaki serin proteazları da inhibe eder. Heparin olasılıkla makrofajların PA salgılamasını uyarır ve ayrıca PA aktivitesini de doğrudan uyararak plazminojenin aktivitesini artırır. Böylece adezyon oluşumunun ikinci fazı olan fibrin depolanması azalır, sonuç olarak adezyon oluşumu engellenir. Literatürde DMAH'lerin adezyon şiddetini azaltıcı etkisinin kontrol grubuna göre üstün olduğunu rapor eden birçok çalışma mevcuttur. Ancak çoğunda mikroskopik olarak inceleme yapılarak makroskopik bulgu desteklenmemiştir [11-13]. Bir çalışmada DMAH uygulanan siçanlarda makroskopik olarak adezyon şiddetinin azaldığı gösterilmiş ancak mikroskopik adezyon skorları bunu desteklememiştir [14]. Araştırmamızda enoksaparin grubunda mikroskopik adezyon skorunun kontrol grubundan istatistiksel olarak farklı bulunmaması makroskopik olarak saptanan adezyon şiddet skorunun kontrol grubuyla benzerlik göstermesini desteklemektedir. Bu durum diğer çalışma grupları için de geçerlidir. DMAH'lerin adezyon yaygınlığını azalttığına dair araştırmalar bulunmaktadır $[15,16]$. Bu çalışmalardaki bulgular bizim sonuçlarımızla paralellik göstermektedir. DMAH'lerin total adezyon skorunu azalttığına dair deneysel araştırmalar da literatürde yer almaktadır [15, 17]. Bu yayınlardaki bulgular bizim çalışmamızdaki ile benzerlik göstermektedir. DMAH'lerin total adezyon skorunu azaltmadığına dair raporlar da bulunmaktadır [18, 19]. 
Bizim çalışmamızda enoksaparin adezyon şiddetinden ziyade adezyon yaygınlığını azaltarak total adezyon skorunu kontrol grubuna göre düşük olmasını sağlamıştır.

Rapamisin grubunda adezyon şiddeti diğer gruplarla benzerlik gösterirken adezyon yaygınlık ve total adezyon skorları yalnız kontrol grubuna nazaran daha düşük bulunmuştur. Ayrıca rapamisin grubunun mikroskopik adezyon skoru diğer gruplarla istatistiksel olarak farkl1lık göstermemiştir.

Rapamisin toprak numunesinden elde edilen streptomyces hygroscopicus isimli bakteri ailesinden izole edilmiş bir peptittir. Kemoterapi, organ transplant rejeksiyonu, kardiyak stentlerin açık tutulması, kornea tedavisi gibi birçok alanda kullanılmış ve olumlu sonuçlar alınmıştır. Programlı hücre ölümünü ve apoptozu tetikleyerek bağışıklık sistemini baskilar. Adezyon oluşumunda peritoneal sıvidaki IL-1 $\alpha$, TGF- $\alpha$, EGF, IL-6, TNF- $\alpha$ ve TGF- $\beta$ gibi mediyatörlerin rol aldığ 1 gösterilmiştir. Rapamisin adezyon fizyopatolojisindeki ilk basamak olan inflamasyon fazındaki sitokin üretimini ve ikinci basamak olan fibroblastik aktiviteyi önleyerek etkili olmaktadır. TGF- $\beta$ adezyon formasyonunun diğer hücresel mediyatörlerin aktivasyonunda rol alır. Doku iyileşmesinde anahtar rol oynar ve doku fibrozunu tetikler. Peritoneal sıvıda yüksek konsantrasyonda bulunan TGF- $\beta$ 'nın adezyon formasyonunu artırdığı bilinmektedir. $\mathrm{Bu}$ nedenle çalışmamızda elde edilen sonuca TGF- $\beta$ 'nın, T lenfosit aktivasyonunu önleyerek makrofaj ve mezotelyal hücrelerden üretiminin engellenmesi yoluyla azalmasında katkısı olabileceği muhtemeldir [8, 20-25]. Sıçanlar üzerinde 2006 yılında yapılan bir çalışmada rapamisinin oral kullanımıyla adezyon önleyici etkisi araştırılmış ve mikroskopik adezyon skorları kontrol grubundan istatistiksel olarak farklı bulunmamıştır. Makroskopik olarak ise rapamisinin adezyonları anlamlı derecede azalttığı rapor edilmiştir. Bu çalışmada adezyon değerlendirmesi "Nair sınıflaması" ile yapıldığından adezyon şiddetine ve yaygınlığına dair ayrı bir skorlama rapor edilmemiş total adezyon skorları verilmiştir [8]. Maciver ve ark. [26] sıçanlar üzerinde yaptığı bir çalışmada ise polipropilen meş ile birlikte rapamisin karın duvarı fitı̆̆ında kullanılmış ve adezyon şiddetinin azaldığı bildirilmiştir. Ancak bu araştırmada mikroskopik adezyon skoru çalışılmamıştır. Akbaba [8]'nın çalışmasında da farklı adezyon skorlaması kullanılmasına rağmen rapamisinin total adezyon açısından kontrol grubuna göre önemli düzeyde önleyici etki saptanmıştır. Araştırmamızın sonuçları bu çalışmadaki bulgularla benzerlik göstermektedir.

Enoksaparin ve rapamisinin birlikte kullanıldığ grupta aynı enoksaparin ve rapamisin gruplarında olduğu gibi adezyon şiddeti diğer gruplardan istatistiksel olarak farklılık göstermezken adezyon yaygınlık ve total adezyon skorları yalnız kontrol grubuna göre istatistiksel olarak anlamlı oranda düşük bulunmuştur. Aynı şekilde kombine grubun mikroskopik adezyon skoru diğer gruplara göre istatistiksel olarak benzerlik göstermiştir.

DMAH'ler tek başlarına veya başka ajanlarla birlikte adezyon önleme amacıyla kullanılmıştır. Kombine kullanıldıklarında genellikle diğer ajanların etkisini arttırmıştır. Piroksikam veya hyaluronik asit gibi adjuvanlar ile birlikte kullanıldığında sinerjistik etkiye yol açtığı gösterilmiştir [11-14]. Çalışmamızda enoksaparin ve rapamisinin birlikte kullanıldığı kombine grubun adezyon şiddeti, adezyon yaygınlığı ve total adezyon yönlerinden sinerjistik bir etkiye sahip olmadığı saptanmıştır. Bu ajanlar tek başlarına kullanılmalarına göre daha üstün adezyon önleyici etki sağlamamışlardır.

Sonuç olarak, deneysel araştırmamızın bulgularına göre enoksaparin ve rapamisin benzer oranlarda total adezyonu azaltmaktadır; bunu yaparken adezyon şiddetinden daha çok adezyon yaygınlığını azaltarak etkili olmaktadır ve birlikte kullanımlarında ise adezyon şiddeti, adezyon yaygınlığı ve total adezyon skorları değişmemektedir. Her iki ajanın başka adjuvanlar ile kombine kullanımlarının denenerek adezyon önlemedeki değerlerinin araştırılmasına yönelik çalışmaların devam etmesinin uygun olacağ kanısindayı. 


\section{Kaynaklar}

1. Liakakos T, Thomakos N, Fine PM, Dervenis C, Young RL. Peritoneal adhesions: etiology, pathophysiology, and clinical significance. Recent advances in prevention and management. Dig Surg 2001; 18: 260-73.

2. ASRM collobaration with the Society of Reproductive Surgeons. Pathogenesis, consequens and control of peritoneal adhesions in gynecologic surgery. Fertil Steril 2008; 90: 144-9.

3. Coleman MG, McLain AD, Moran BJ. Impact of previous surgery on time taken for incision and division of adhesions during laparotomy. Dis Colon Rectum 2000; 43: 1297-9.

4. Metwally M, Watson A, Lilford R, Vandekerckhove P. Fluid and Pharmacological agents for adhesion prevention after gynaecological surgery. Cochrane Database Syst Rev 2006; 19: CD001298.

5. Miller G, Boman J, Shrier I, Gordon PH. Etiology of small bowel obstruction. Am J Surg 2000; 180: 33-6.

6. Kamel RM. Prevention of postoperative peritoneal adhesions. Eur J Obst Gyn 2010: 150; 111-8.

7. Kanko M, Ozbudak E, Ozerdem A, Aksoy A, Kilic M, Berki KT. Effect of sirolimus in the prevention of adhesions around intraabdominal prosthetic graft. World J Surg 2006; 30: 1648.

8. Akbaba P. Rapamisin'in ratlarda deneysel olarak oluşturulan intraabdominal adezyonların gelişimi üzerine etkisi. Uzmanlık tezi. 2006.

9. Linsky CB, Diamond MP, Cunningham T, Constantine B, DeCherney AH, diZerega GS. Adhesion reduction in the rabbit uterine horn model using an absorbable barrier, TC-7. J Reprod Med 1987; 32: 17-20.

10. Rose J, Jayaraman S, Colquhoun P, Taylor B. Minimal abdominal adhesions after Sepramesh repair of a parastomal hernia. Can J Surg 2009; 52: 211-2.

11. Tayyar M, Turan R, Ayata D. The use of amniotic membrane plus heparin to prevent postoperative adhesions in the rabbit. Tokai J Exp Clin Med 1993; 18 : 57-60.

12. Tayyar M, Başbuğ M. The effects of intraperitoneal piroxicam and low molecular weight heparin in prevention of adhesion reformation in rat uterine horn. Res Exp Med 1999; 198: 269-75.

13. Başbuğ M, Aygen E, Tayyar M, Kaya E, Narin F, Oktem O. Hyaluronic acid plus heparin for improved efficacy in prevention of adhesion formation in rat uterine horn model. Eur J Obstet Gynecol 1998; 78: 109-12.

14. Altun Ö, Tayyar AT, Tayyar A, Özgün T, Öztürk F, Tayyar M. Siçanlarda oluşturulan deneysel uterin horn adezyon modelinde düşük molekül ağırlıklı heparin ile oktreotid'in karşılaştırılması. Cumhuriyet Med J 2012; 34: 307-13.

15. Türkçapar AG, Ozarslan C, Erdem E, Bumin C, Erverdi N, Kutlay J. The effectiveness of low molecular weight heparin on adhesion formation in experimental rat model. Int Surg 1995; 80: 92-4.

16. Diamond MP, Linsky CB, Cunningham T, Kamp L, Pines E, DeCherney AH, diZerega GS. Adhesion reformation: reduction by the use of Interceed (TC7) plus heparin. J Gynecol Sum 1991; 7: 1.

17. Fukasawa M, Girgis W, diZerega GS. Inhibition of postsurgical adhesions in a standardized rabbit model: II. Intraperitoneal treatment with heparin. Int J Fertil 1991; 36: 296-301.

18. Reid RL, Hahn PM, Spence JE, Tulandi T, Yuzpe AA, Wiseman DM. A randomized clinical trial of oxidized regenerated cellulose adhesion barrier (Interceed, TC7) alone or in combination with heparin. Fertil Steril 1997; 67: 23.

19. Perju D, Lupaşcu C. Comparative experimental study of the effect of various locally administered pharmacological agents on the appearance of peritoneal adhesions. Rev Med Chir Soc Med Nat Iasi 2006; 110: 116-21. 
20. diZerega GS. Biochemical events in peritoneal tissue repair. Eur J Surg Suppl 1997; 577: 10-6.

21. Rodgers KE, diZerega GS. Function of peritoneal exudate cells after abdominal surgery. J Invest Surg 1993; 6: 9-23.

22. Kaidi AA, Nazzal M, Gurchumelidze T, Ali MA, Dawe EJ, Silva YJ. Preoperative administration of antibodies against tumor necrosis factor-alpha (TNF-alpha) and interleukin-1 (IL-1) and their impact on peritoneal adhesion formation. Am Surg 1995; 61: 569-72.

23. Başoğlu M, Kızıltunç A, Akçay F, Keles S, Gündoğdu C, Ören D. D. Tumor necrosis factor- $\alpha$ and interleukin-6 in peritoneal adhesion formation. Tr J Med Sci 1998; 28: 253-8.

24. Banaszynski LA, Liu CW, Wandless TJ. Characterization of the FKBP.rapamycin.FRB ternary complex. J Am Chem Soc 2005; 127: 4715-21.

25. Liu L, Chen L, Chung J, Huang S. Rapamycin inhibits F-actin reorganization and phosphorylation of focal adhesion proteins. Oncogene 2008; 27: 4998-5010.

26. Maciver AH, McCall MD, Edgar RL, Thiesen AL, Bigam DL, Churchill TA, Shapiro AM. Sirolimus drug-eluting, hydrogel-impregnated polypropylene mesh reduces intra-abdominal adhesion formation in a mouse model. Surgery 2011; $150 ; 907-15$. 